\title{
A comparison of Taiwanese sign language and manually coded Chinese: word length and short-term memory capacity
}

\author{
Hsiu-Tan Liu ${ }^{1}$, Chin-Hsing Tseng ${ }^{2}$ and Chun-Jung Liu ${ }^{1}$ \\ ${ }^{1}$ Chung Shan Medical University, Taiwan, R.O.C. \\ ${ }^{2}$ National Kaohsiung Normal University, Taiwan, R.O.C. \\ https://doi.org/10.36505/ExLing-2008/02/0036/000095
}

\begin{abstract}
Taiwanese Sign Language (TSL) is the natural language among deaf communities in Taiwan. Manually Coded Chinese (MCC) is the official instructional language. Previous studies have shown that the deaf students have great difficulty in comprehending stories in MCC, plausibly due to greater word length in $\mathrm{MCC}$, which in turn may impair recall of MCC words. In Study I, deaf and hearing signers produced signs for 100 words in both MCC and TSL, and the word length was calculated for each sign pairs. It was found that MCC words were greater in length than the TSL words, whether produced by a hearing or a deaf signer. In Study II, the short-term memory capacity in the deaf signers was compared between word lists in TSL and in MCC. The participants were 44 senior high students in the deaf school and 20 deaf adults. The results showed that for deaf students and adults, the short-term memory capacity was inferior for the MCC list than for the TSL list, confirming our hypothesis.
\end{abstract}

Key words: Taiwanese sign language, manually coded Chinese, word length, shortterm memory

\section{Introduction}

In Taiwan, sign language is divided into two categories: Taiwanese Sign Language (TSL) and Manually Coded Chinese (MCC). TSL is the natural sign language used among the deaf communities. MCC is the official instructional language. It lays stress on the expression based on sequence of spoken language. Its vocabulary is developed by sign language research and development team.

Deaf communities did not accept MCC quite well. The deaf students only used MCC in class, but tend to use TSL during their leisure time outside of class. The previous studies found that the deaf student could comprehend the stories in TSL, but had great difficulty in comprehending the ones in MCC.

Why could deaf students not comprehend the stories in MCC easily? Supalla (1991), Hoffmeister (2000), and many other scholars believed that Manually Coded English combined the sign of visual language and the grammar of audible language, which may cause comprehending difficulties and cognitive memory load for the deaf students. We believe that the

ExLing 2008: Proceedings of 2nd Tutorial and Research Workshop on Experimental Linguistics, 25-27 August 2008, Athens, Greece 
sequential expression of MCC based on spoken language and the way of making signs one by one would cost much time and lead to extremely long word length, which might cause load on the deaf people's cognitive memory. That is the reason why they could not comprehend the stories in MCC easily.

This research assumes that the word length of MCC is greater than that of TSL, and the short-term memory capacity is inferior to that of TSL. In this research, Study I is the practical comparison between the word length of MCC and that of TSL, while Study II is the comparison between the shortterm memory capacities of both languages.

\section{Study I}

The major purpose of this study is to compare the word length of TSL and MCC. The experimental design used two-way ANOVA. The independent variables were the hearing status, and the sign language categories. The dependent variable was the word length of TSL and MCC produced by deaf signers and hearing signers. The participants in this study are 10 deaf adults and 10 hearing signers. The researcher sampled 100 words from sign language dictionary at random and required the participants to sign the words with these two sign languages respectively.

\section{Results}

The average length of the 100 words signed by the participants in this study had been sorted and listed in Figure 1.

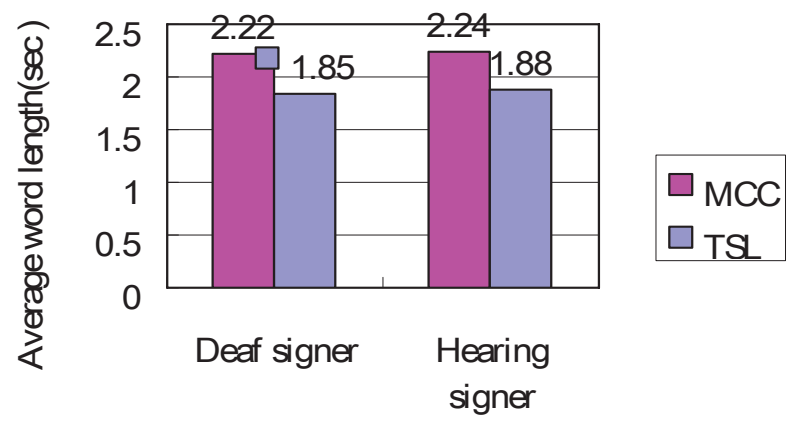

Figure1.Comparision of word length in MCC and TSL.

It was found from Figure 1 that MCC words length were greater than the TLS words both signed by hearing and deaf signers. 


\section{Study II}

The purpose of Study II is to compare the deaf signers' working memory capacities when they face the different morphologies. The independent variables of two-way ANOVA were age and morphology. The dependent variable was the sign language word memory capacity. The treatment levels of the age variable were deaf adults and deaf students. The morphology includes MCC borrowed words(MCC-B), MCC added pleonasms(MCC-A), MCC concatenated words(MCC-C), and TSL compounds(TSL).The MCC $\mathrm{C}$ indicates that MCC borrows the words from TSL. It has only one sign, and it is signed identically by either MCC or TSL. In this study we called them TSL simple words (TSL-S). Both the MCC-A and MCC-C words were the sign language word combined with two signs. The TSL-C refers to the word with two signs in TSL. In the experimental material, the speeds of the four kinds of sign language words were adjusted to make no distinction exist in word length of the four kinds of sign languages. The participants were 44 senior high deaf students from Deaf School and 20 deaf adults.

\section{Results}

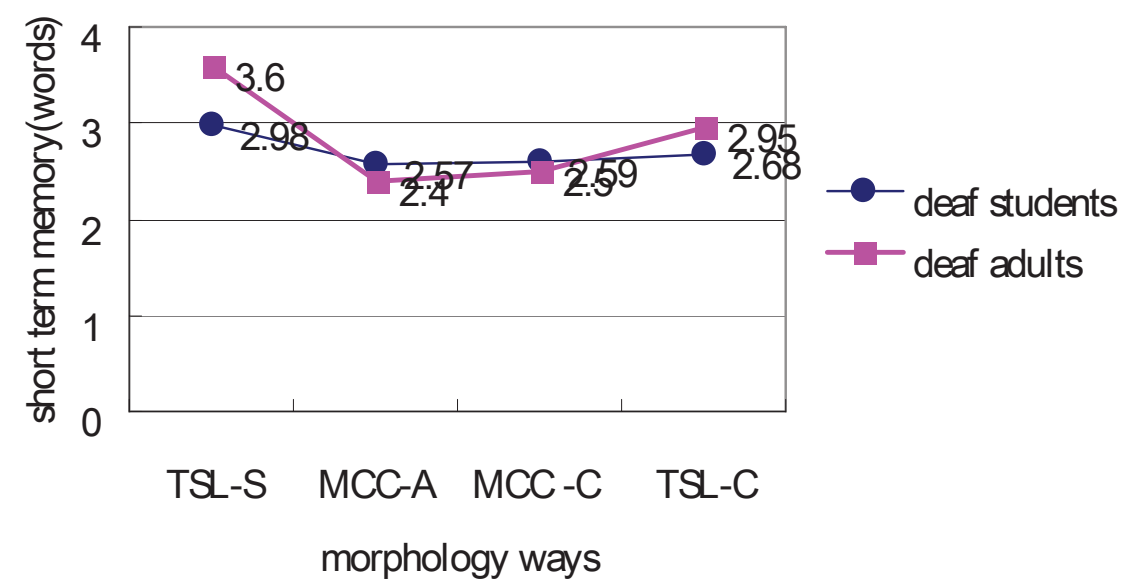

Figure2. Deaf signers' memory capacity of different morphology ways.

For the deaf students, TSL-S words memory extent was superior over MCC-A and MCC-C words.

For the deaf adults, the short-term memory capacity in TSL-S was superior than that in the other three kinds of sign language words (MCC-A, MCC-C, TSL-C), and the short-term memory capacity in TSL compounds was also superior than that in MCC-A and MCC-C. 


\section{Conclusion and discussion}

This research has proven that MCC is greater in word length than TSL, and the short-term memory capacity of deaf people in MCC words is inferior to that in TSL words.

The deaf people have a poor short-term memory capacity in MCC words, and that may have resulted from the effect of word length. However, Study II in this research still indicates that, for deaf students, the memory capacity was inferior for the MCC list than for the TSL list under the circumstance that the word length is under control. It indicates that other factors besides the word length may also have an effect of the deaf students' memory capacity when they memorize sign language words.

Memory is a key part in the cognitive process, so the educators should envisage the problem that deaf students have difficulties in memorizing $\mathrm{MCC}$ and resurvey the applicability of MCC to instruction.

\section{References}

Supalla, S. 1991. Manually coded English: The modality question in signed language development. In P. Siple, and S. Fischer (Eds.), Theoretical issues in sign language research: Acquisition (pp. 85-109). Chicago: University of Chicago Press.

Hoffmeister, R. J. 2000. A piece of the puzzle: ASL and reading comprehension in deaf children. In C. Chamberlain, J. P. Morford, and R. I. Mayberry (Eds.), Language acquisition by eye (pp. 143-164). Mahwah, NJ: Lawrence Erlbaum Associates. 